\title{
Reputation and Organizational Efficiency: A Data Envelopment Analysis Study
}

\author{
Carl Brønn \\ The Norwegian University of Life Sciences, Norway \\ Peggy Simcic Brønn \\ The Norwegian School of Management, Norway
}

\begin{abstract}
In the spirit of the resource-based view, resources can be treated as 'stocks' that are used by the firm in its activities. Managerial actions influence, both directly and indirectly, the quantities of the resource stock by 'filling' or 'emptying' them. Consequently, it is important for the organization to have a measure of the state of the resource stock, as well as an understanding of how different actions affect their level. In this sense, for any managerial measure to be useful, it should be operationoriented and not simply an indicator of past performance. In this paper, the Data Envelopment Analysis (DEA) methodology is proposed as a way to view reputation from another angle - from inside the organization. The approach is described by means of an example based on data similar to that employed in the reputation quotient (RQ). The implications for applying it to the six attributes that define the RQ are discussed. The authors believe the results of a $D E A$ investigation can lead to an assessment of the internal operational aspects of reputation and thereby can assist practicing managers to better utilize this strategic resource.
\end{abstract}

KEYWORDS: Reputation, DEA, organizational efficiency, intangible resources, measurement

\section{INTRODUCTION}

'The first step is to measure whatever can be easily measured. This is $\mathrm{OK}$ as far as it goes. The second step is to disregard that which can't easily be measured or give it an arbitrary quantitative value. This is artificial and misleading. The third step is to presume that what can't be measured easily really isn't important. This is blindness. The fourth step is to say that what can't be easily measured really doesn't exist. This is suicide.'

(Yankelovich, 1972)

Reputation is both a complex and increasingly relevant construct upon which managers and academics are focusing their attention. The Reputation Institute (RI), through its work, has identified 20 indicators that are used as the basis for their reputation quotient (RQ). This is an important measure that ranks organizations based on respondents' perceptions of six attributes, which are based on these indicators. In this paper, an approach is proposed that builds on the work of the RI. By means of an example and accessible data similar to the RQ methods and attributes, the authors introduce a quantitative methodology called Data Envelopment Analysis (DEA) that enables computation of a multidimensional efficiency measure derived from organizations' actual performance on several attributes to compare their relative performance. As the selected dimensions chosen here mirror the RQ attributes, it is reasonable to hypothesize that the resulting
Corporate Reputation Review, Vol. 8, No. 1, 2005, pp. 45-58 C) Henry Stewart Publications, 1363-3589 
efficiency measures will be positively correlated with the RQ.

By comparing organizations on their efficiencies of use, which will be defined later, managers and academics may be able to understand the internal processes by which reputation is built and maintained. This paper's focus is on those issues over which management (in principle) has control. This perspective is consistent with the dynamic resource-based view of strategy (Wernerfelt, 1984; Dierickx and Cool, 1989; Barney, 1991) and points the way for managers to actively manage this 'soft' resource.

The economist John Kay (1996) defines four distinctive capabilities that he claims give an organization competitive advantage. These are architecture, reputation, innovation and strategic assets. Competitive advantage accrues to the firm through reputation because it is rare, valuable, not substitutable and difficult to copy (Roberts and Dowling, 2000).

Reputation is not owned by the firm as if it was a product, it does not allow return-on-reputation computations similar to discounted cash flow calculations on equipment and its cost cannot be measured because image or reputation is not part of the general ledger accounts. Low and Kalafut (2002), on the other hand, list 12 intangible assets of an organization, which include brand and reputation. These assets are not on a balance sheet or income statement, but they do add to value creation and, according to the authors, they can be managed and quantified.

Even though researchers are seeking accounting principles that allow reputation to be quantified as a financial asset of an organization, there exists considerable work demonstrating that reputation can be quantified in other ways. Much of this work comes from a number of ranking barometers, the most notable of which are Fortune Magazine's 'Top 10 Most Admired
Companies in the US' and the Financial Times' 'Most Admired Companies in Europe'. The RQ, which is the basis for this paper, is the newest entry to these international barometers.

Common to these barometers is that they rank organizations according to a list of what they refer to as 'reputation attributes'. Bromley (2002) refers to these types of barometers as league tables. They are generated from large samples of respondents who rate a selection of companies on various attributes that are relevant to corporate success. They are valid tools from which stakeholders can gather impressions of organizations based on quantifiable data. The data can be used for benchmarking, or comparing a firm against industry averages or against the industry leader, thereby providing insight that may be useful, for example, in strategic planning.

The methodology proposed here is similar to the RQ in that one of the analysis outputs is a 'ranking', but it adds an additional dimension. While rankings are interesting, they are essentially 'backwardslooking' and are often based on perceptions of the organization made by external respondents. The outcomes are based on historical data and do not provide much insight into how the ranking was achieved, ie what the organization actually did to impact the reputation attributes. The RQ also provides a firm with attribute weights, which give some indication of the relative importance of the six reputation attributes to the respondents. The authors' proposal is based on the methodology called Data Envelopment Analysis (DEA), which also gives a ranking and attribute weights but in addition, and importantly for reputation managers, gives an indication of how firms perform internally on the attributes that, as described by Dowling (2001), can be viewed as being embedded inside the firm. This will be explained later in the paper.

The paper is organized as follows. First, 
a brief overview of the RQ is presented and then the method, DEA, is presented and explained. The authors use an extended example based on data from the Norwegian Customer Satisfaction Barometer, ${ }^{1}$ which has methodological similarities to the RQ. Then the DEA and RQ findings are compared and discussed. The paper concludes with a discussion of the managerial implications of the DEA approach.

\section{MEASURING ORGANIZATIONAL PERFORMANCE}

Organizational performance is a complex and critically important multidimensional construct. In thinking about organizational performance, however, it is important to keep in mind what the concept 'performance' entails and what it means with respect to measurement. Recognizing that organizations are systems of productive assets (including individuals and tangible and intangible assets) that come together for, among other things, obtaining economic advantage, the relevant performance measures should then compare the value of the organization's output using the productive input assets with the value that the asset owners expect to receive (Barney, 1996).
Traditional single value performance measures (such as financial indicators) are popular as they are easy to observe and to understand. They have problems, however, that make them incomplete and therefore unreliable as a sole basis for assessment. Among these problems are the insensitivity of financial measures to intangible assets such as reputation and the fact that they do not address the fundamental value-creating activities upon which the firm relies to create value. Additionally, financial measures are based on past performance and are not forward-looking; an undesirable feature in a turbulent environment.

Applying a multiple stakeholder approach to performance measurement fills out the conceptual definition of organizational performance. One such multi-stakeholder measure is the RQ. The RQ is a measure of organizational performance that is based on six attributes (Figure 1) that represent different and important clusters of resources and competencies that are employed by organizations in performing their activities.

The RQ provides guidance for managers concerned with the reputation asset.

Figure 1: Elements of the reputation quotient (RQ)

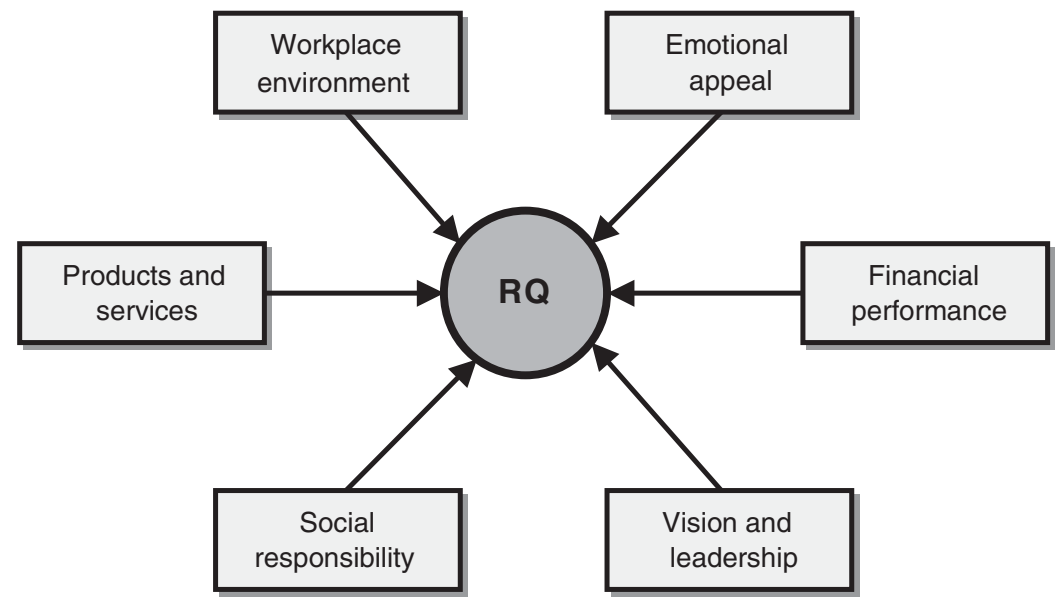


It presents organizations with a ranking of how they stand in comparison with other firms and, as all firms are unique, one can assume that there will be differences in the emphasis placed on the attributes. Through regression analysis and structural equation modeling, the RQ then calculates weighted attribute scores, both collectively and by individual participating firms. The attribute weights indicate the importance of each attribute in the calculation of the RQ value. The results are typically presented for a sample of firms and follow-up studies can be conducted for individual firms. In the following section, a methodology is proposed - DEA - that provides a means of ranking the specific firms, yet also gives different information about the importance of the attributes. DEA extends the usefulness of the $R Q$ research by adding the concept of the efficient frontier, which can be compared to the notion of best practices. This latter feature should be of special interest to reputation managers.

\section{THE DATA ENVELOPMENT ANALYSIS APPROACH TO PERFORMANCE MEASUREMENT}

\section{Background}

DEA, developed by Charnes et al. (1978), is a linear programming-based method for computing relative performance of socalled 'decision-making units' (DMUs). DMUs may be defined as individual firms, sub-units within a firm, or even individual human decision makers (Chilingerian, 1994). The initial applications of DEA were in comparing public sector decision-making units, such as public schools, medical facilities and police stations, as well as in private sector applications such as bank branches. These studies investigated performance of similar units to identify best practices and to provide assistance to less well performing units in order for them to achieve better performance compared with the higher performing units. For example, in a business firm, resource inputs such as capital, labor and fixed assets are transformed into outputs, normally in the form of products, realized profits and satisfied customers. Thus, for each DMU/firm, the DEA approach computes a multidimensional measure of performance for each DMU relative to its cohorts, the firms against which it is compared. More recently, DEA has been applied to investigating the corporate-stakeholder relationship with the intent to identify best practices (Bendheim et al., 1998). Bendheim et al. (1998) used constructs that are similar to those in the RQ.

The DMU performance measure is a relative efficiency, which is defined as the ratio of outputs to inputs. In the business context, increased efficiency can result from (1) producing greater output for a fixed set of inputs, (2) maintaining output at reduced levels of inputs, or (3) a combination of the two. For complex systems with multiple inputs and outputs, the efficiency term is taken to be the ratio of a weighted sum of outputs to the weighted sum of a set of inputs. The assignment of weights is a central issue in computing the relative efficiency, however, it is unrealistic to assume that a common set of weights will apply to all DMUs. The inputs and outputs of any complex system, such as an organization, may be incommensurate and that makes direct comparisons of systems difficult. By arguing that each DMU has its own value system that guides its input-output process (Boussofiane et al., 1991), the problem of establishing a common weight system can be avoided.

A basic DEA study produces the following information: 
It identifies the efficient frontier, or envelopment surface, of the 'best practices' firms, which have 100 per cent relative efficiency.

- It calculates a relative efficiency measure that reflects the distance of each inefficient $(<100$ per cent) firm from the best practices frontier.

- It provides projections for each inefficient firm, ie those below the efficient frontier, in the form of targets to be achieved in order to become efficient.

- It identifies efficiency reference groups, called a 'peer group', which are defined by a subset of the efficient firms that are closest to the inefficient firm under evaluation.

Other studies can be linked to the results of a DEA study. Some possibilities include:

- Detailed studies of different types of inefficiencies.

- Calculation of economies of scale.

- Setting realistic and achievable targets for inefficient firms.

- Investigating managerial tradeoffs that have resulted in inefficient scores.

- Statistical analyses of relationships to environmental variables and technological differences.

- Changes in efficiency and reputation over time.

- Triple bottom line potential by including specific corporate social responsibility indicators.

\section{Theoretical Basis}

DEA is an alternative approach to extracting information from a set of observations about a population of interest. Rather than taking a parametric approach to constructing a regression plane through the set of observations, DEA is a non-parametric methodology that considers each observa-
Figure 2: A generic two-input, three-output decision-making unit (DMU)

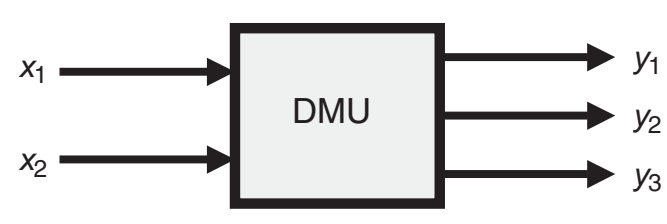

Input measures

Output measures

tion and optimizes on each with the objective of computing a frontier of Pareto efficient DMUs (Charnes et al., 1994). This method stands in contrast to the concept of the 'average' DMU resulting from other traditional parametric approaches such as regression analysis.

The general model of a DMU is shown in Figure 2. Performance is based on the DMU 'converting' several input variables, or 'costs', $x_{1}, x_{2}$, into output variables, or 'benefits', $y_{1}, y_{2}, y_{3}$.

The efficiency of a specific DMU, the 'target unit' $j 0$, is obtained by solving the model:

$$
\operatorname{Max} h_{0}=\frac{\sum_{r=1}^{t} u_{r} \gamma_{r j 0}}{\sum_{i=1}^{m} v_{i} x_{i j 0}}
$$

Subject to the constraints:

$$
\frac{\sum_{r=1}^{t} u_{r} y_{r j}}{\sum_{i=1}^{m} v_{i} x_{i J}} \leq 1 j=1,2,3, \ldots, n,
$$

such that $u_{r}, v_{i} \geqslant \varepsilon$, for all $r$ and $i$.

Where:

$h_{0}=$ efficiency of the target decisionmaking unit

$y_{r j}=$ amount of output $r$ from unit $j$

$x_{i j}=$ amount of input $i$ to unit $j$

$u_{r}=$ the weight given to output $r$

$v_{i}=$ the weight given to input $i$

$n=$ the number of units being compared

$t=$ the number of outputs

$m=$ the number of inputs

$\varepsilon=$ a small positive number. 
Figure 3: The efficient frontier

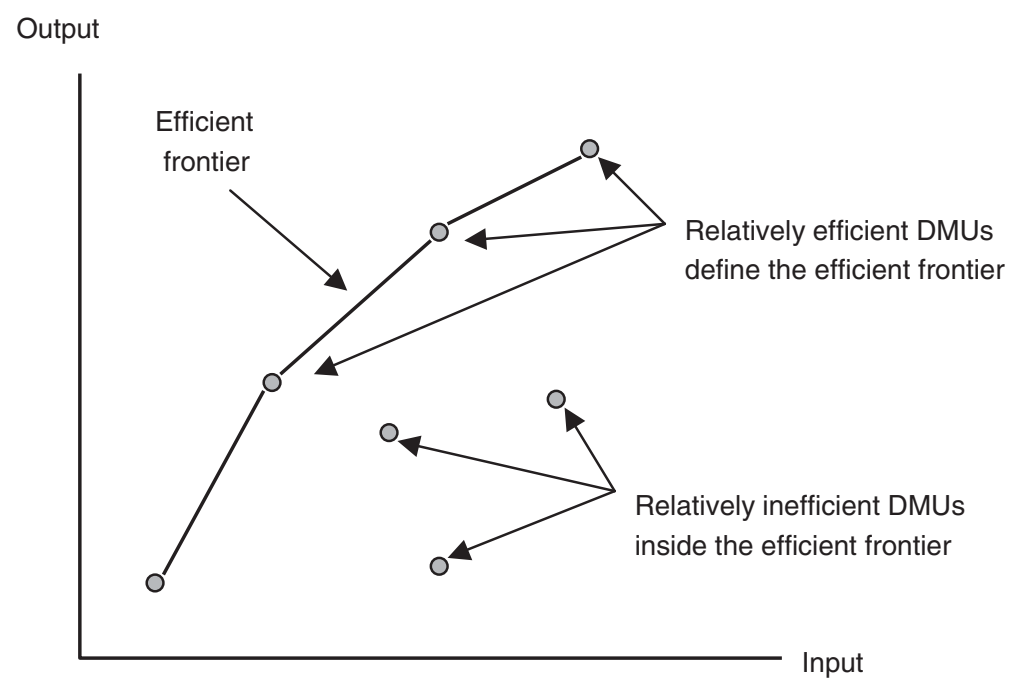

The notion of the 'efficient frontier' separates efficient units from inefficient units. DMUs lying on the efficient frontier are defined as being 100 per cent efficient with respect to the other units in the analysis. Inefficient DMUs are found inside the frontier. Figure 3 illustrates the general situation for a group of seven DMUs.

In this figure, the DMUs defining the efficient frontier are efficient as their input to output ratios are 100 per cent. These units can be viewed as best practice firms with respect to their use of inputs to create outputs and thus are benchmarks against which other units can compare their performance. Those below the line are inefficient with respect to the efficient frontier, that is, they are not optimizing their use of inputs to create outputs.

\section{Applying DEA}

A simple example based on data from the Norwegian Customer Satisfaction Barometer (CSB) (2002) demonstrates the application and interpretation of the DEA method. The CSB (Fornell, 1992; Johnson et al., 2001) is similar in many ways to the $\mathrm{RQ}$, for which data were not available. The CSB is based on data from a questionnaire that is completed by respondents in a telephone interview. There are a total of 52 questions that are grouped into the following categories: Demographic/ Background, Satisfaction (four questions), Price (three questions), Physical/Material Quality (three questions), Response Adequacy (five questions), Personal Treatment (six questions), Fairness (three questions), Complaint Handling (two questions), Reputation (four questions), Trust (three questions), Affective Bond (four questions), Economic Bond (four questions), Behavioral Intention (four questions) and Relationship Phase (four questions). The barometer responses are scored on a tenpoint scale where $1=$ 'to a low degree' and $10=$ 'to a high degree'. Favorable responses score higher. The organizations (DMUs) in this example are six 'large' Norwegian banks. Names from Norse mythology have been used here to disguise them. 
The DEA application presented by Bendheim et al. (1998) used a model in which all of the stakeholder relation variables were outputs. A dummy variable was used as the single input variable. The DEA model presented in the following example specifies attributes as either inputs or outputs. As discussed later, the RQ attributes can be naturally interpreted in an input and output sense. Explicitly formulating the model in this manner allows the results to be interpreted in an operational sense: what reputation managers can do in order to improve their firm's ranking.

For this study and in order to simplify the example, the authors considered a twoinput (price and quality), single-output (reputation) model to compare the banks' performance. Keller (1998) discusses a number of attributes that are associated with reputation, including product characteristics such as quality. Additionally, according to Keller, consumers associate pricing policies with certain images. High prices are often associated with specialized, high quality products, for example. Table 1 below gives the selected data from the CSB and the banks' overall ratings using the entire set of CSB variables.

In DEA, the inputs are generally seen as costs, which are usually minimized in order to improve efficiency. In the CSB, however, the scores are given such that high ratings mean better performance for the variables. In order to keep the interpretation of the inputs as costs (to be minimized) and outputs as benefits (to be maximized), the two input variables have been reverse-scored by subtracting them from 10. This keeps the interpretation of the DEA output data in line with intuition. One strategy for improving organizational efficiency is to minimize costs (making the reversed scores smaller). Clearly, Balder outranked the other banks in overall customer satisfaction, even when only considering the three attributes here, while Odin was ranked the lowest of the six.

DEA is claimed to be an 'objective' evaluation technique because of its straightforward LP-based calculation procedure. An element of subjectiveness, however, enters the analysis through the selection of the relevant input and output factors. This decision is very important and must be carefully considered in the design of the analysis. These issues are discussed in the context of the RQ later in this paper. The authors are interested in comparing six banks as the decision-making units. Using only the inputs (reversed) price and (reversed) quality and output reputation and employing a commercially available DEA program, the banks have the following relative efficiencies, summarized in Table 2.

Table 1: Bank Examples Using Price, Quality, Reputation Attributes and Overall Ranking Using Attributes from the Norwegian Customer Satisfaction Barometer (CSB)

\begin{tabular}{lllll}
\hline Bank & Price & Quality & Reputation & $\begin{array}{l}\text { 2002 CSB overall } \\
\text { ranking }\end{array}$ \\
\hline Balder & 4.11 & 2.45 & 7.38 & 1 \\
Loki & 3.85 & 2.83 & 6.83 & 2 \\
Thor & 4.11 & 2.77 & 6.73 & 3 \\
Freya & 4.01 & 2.54 & 6.99 & 4 \\
Njord & 4.07 & 2.74 & 6.41 & 5 \\
Odin & 5.58 & 3.76 & 5.79 & 6 \\
\hline
\end{tabular}

* Reverse scored by subtracting the raw value from 10 . 
The relative efficiency calculations permit the authors to rank order the DMUs, in a manner similar to the RQ. Because the rankings are based on different methodologies, one cannot expect the two to be the same. It is possible, however, to expect a high correlation between the scales, as they are based on similar data. As the only efficient bank in the data set, Balder, in conjunction with the origin point of the data space, defines the efficient frontier. The remaining banks lie beneath the frontier, with Odin being the least efficient. These five banks have the possibility to improve their positions by making changes in their disposition of the inputs and outputs.

From a managerial perspective, perhaps the most useful information provided by a DEA study is that which indicates what improvements must be made in order for an inefficient DMU to become efficient with respect to the efficient DMUs against which it is being compared. This information is given in the table of target values.
The table of target values is a standard DEA output and indicates the magnitude of the changes in outputs and inputs that are needed to move the DMU under consideration up to the efficient frontier. The input-output values are computed based on the analysis of a DMU's 'peers', the nearby efficient DMUs.

Odin is the least efficient (57.8 per cent) of the six banks in this example. The actions available to Odin's management to make the bank more efficient are: (1) keeping the input levels constant and increasing the output, (2) holding outputs constant and decreasing the inputs or (3) a combination of decreasing inputs and increasing outputs. The feasibility of these changes must, of course, be carefully evaluated for each DMU. In this example, reducing the output reputation is not an option. It is possible, however, to reduce the levels of the two input variables. Actions taken by Odin's management to improve the scores on price and quality could improve the

\section{Table 2: DEA Efficiency Calculation Results and Ranking}

\begin{tabular}{lcc}
\hline Bank & Efficiency $(\%)$ & DEA efficiency ranking \\
\hline Balder & 100.0 & 1 \\
Loki & 98.8 & 2 \\
Freya & 97.1 & 3 \\
Thor & 91.2 & 4 \\
Njord & 87.7 & 5 \\
Odin & 57.8 & 6 \\
\hline
\end{tabular}

Table 3: Input Minimization Target Values for Odin Bank

\begin{tabular}{|c|c|c|c|}
\hline Variable & $\begin{array}{l}\text { Actual values } \\
\text { (see Table 1) }\end{array}$ & $\begin{array}{l}\text { Target values } \\
\text { (DEA analysis) }\end{array}$ & $\begin{array}{l}\text { Improvement } \\
\text { potential }(\%)\end{array}$ \\
\hline Input $1-$ Price $^{\star}$ & 5.58 & 3.2 & 42.6 \\
\hline Input $2-$ Quality ${ }^{\star}$ & 3.76 & 1.9 & 49.5 \\
\hline Output 1 - Reputation & 5.79 & 5.79 & 100.0 \\
\hline
\end{tabular}

$\star$ Reverse scored. 
bank's relative efficiency and ranking. The table of target values (Table 3) quantifies the input reductions needed to move Odin Bank to the efficient frontier.

Two important questions remain, however. The first is whether these adjustments can be made and the second is how they are to be accomplished. Further, even though the analysis identifies what changes need to be made, nothing is said about the feasibility of making these changes or how to make these changes. These remain for management to consider, but DEA gives clear targets.

The final output of a simple DEA run is the weights table, Table 4, which indicates the relative importance of the input and output variables in computing the efficiency scores. The attribute weight table is an important output of a DEA study (Doyle and Green, 1994). The weights are computed to maximize each DMU's efficiency, given a set of constraints imposed by the other DMUs in the analysis. The results of the weights calculation may be at variance with management's intuition about the priorities or importance that should be placed on the inputs and outputs. Subsequent evaluation and discussion of the computed weights can lead to refinements in defining constraints for the range of values that the weights can assume. For example, it is possible to delimit the weights calculation to reflect the attitude of management that price is at least twice as important as quality. This relationship can be defined in the DEA setup and the results will reflect this prioritization in the output calculations of efficiency, targets and weightings.

The weights calculated for the inputs and outputs of the six banks are given below in Table 4 . There are significant differences in the distribution of weights between Balder and the five inefficient banks. Balder weights both the price and quality inputs, while the others place their emphasis on price. Although not evidenced in this example, it is worthwhile noting that it is possible for two DMUs to both have 100 per cent relative efficiencies, yet have completely different weight assignments. This may be interpreted as a difference in 'management style' between the two DMUs.

By using only the efficiency scores as the ranking criterion, DEA provides no more information than the situation where two firms have the same RQ and are tied on the ranking. The advantage of DEA is that it also computes the weights for the inputs and the outputs that maximize the DMU's efficiency. These weights are the values of the coefficients $u_{r}$ (outputs) and $v_{i}$ (inputs) in the DEA linear programing algorithm. Investigating the differences in the weighting structures of the two efficient banks can provide information about the underlying importance placed on the attribute inputs and outputs. These results can be used to

Table 4: Weight Assignments to Bank Inputs and Output

\begin{tabular}{lllllll}
\hline & Balder & Loki & Thor & Freya & Njord & Odin \\
\hline DEA efficiency ranking & 1 & 2 & 3 & 4 & 5 & 6 \\
Input 1 - Price & 0.122 & 0.26 & 0.243 & 0.249 & 0.246 & 0.179 \\
Input 2 - Quality & 0.204 & 0.00 & 0.00 & 0.00 & 0.00 & 0.00 \\
Output 1 - Reputation & 0.136 & 0.145 & 0.136 & 0.139 & 0.137 & 0.099 \\
\hline
\end{tabular}

$\star$ Reverse scored. 
guide managerial inquiry regarding the underlying values of the firm and how stakeholders' perceptions of the attributes match the firm's perceptions. This may, in turn, lead to a reallocation of communication efforts on the part of the firm to better represent what it actually stands for. An additional feature of commercial DEA programs allows specification of specific weights or constraints on the range of allowable coefficient values. This enables managers to investigate the effect on overall efficiency of alternate weights that may more accurately reflect the firm's values.

This has been an abbreviated presentation of a methodology that has considerable power to evaluate and analyze organizational performance. The literature of DEA has exploded in recent years, as the technique finds more application as an alternative means for monitoring organizational performance (Seiford, 1990). It is in this spirit that its use is proposed here, in the evaluation of organizational reputation and its attributes.

\section{DEA AND ANALYZING THE COMPONENTS OF REPUTATION}

\section{Applying DEA to the 'RQ-like' Data}

The bank data set introduced in the previous section will continue to be used in order to illustrate the comparison of DEA and the RQ. Table 5 summarizes the results of the comparison between the two methods and includes the ranking from the CSB study. An 'RQ-like' ranking measure has been calculated for the banks, based on the RI's method of averaging the scores on the reputation attributes. Here, the scores on the two-input and one-output variable were averaged. These values are presented in the 'RQ-like' average column of the table. The following columns give the rankings by the three methods.

Although there are some differences in the rankings, they do not appear to be dramatic. All three rankings agree on the best, the next worst and the worst cases; there are some disagreements on the middle group of banks. With the exception of Freya Bank, the rankings differ by only one place across the three methods. In the case of Freya Bank, the ranking scales give it a 2 ('RQ-like'), 3 (DEA) and 4 (CSB).

\section{Applying DEA to the RQ Variables}

The central task in defining and applying a DEA model to studying reputation lies in the specific assignment of reputation attributes as inputs or outputs to the firms under consideration. The validity of the reputation attributes has been discussed elsewhere (Fombrun et al., 2000). The authors propose an assignment of the reputation attributes to input or output

Table 5: Comparison of Ranking Methods

\begin{tabular}{llllllll}
\hline Bank & Price & Quality & Reputation 'RQ-like' & $\begin{array}{l}\text { 'RQ-like' } \\
\text { average } \\
\text { ranking }\end{array}$ & $\begin{array}{l}\text { DEA } \\
\text { ranking }\end{array}$ & $\begin{array}{l}\text { 2002 CSB } \\
\text { ranking }\end{array}$ \\
\hline Balder & 5.889 & 7.55 & 7.379 & 6.939 & 1 & 1 & 1 \\
Loki & 6.150 & 7.17 & 6.835 & 6.718 & 3 & 2 & 2 \\
Freya & 5.986 & 7.46 & 6.989 & 6.812 & 2 & 3 & 4 \\
Thor & 5.886 & 7.23 & 6.732 & 6.616 & 4 & 4 & 3 \\
Njord & 5.927 & 7.26 & 6.413 & 6.533 & 5 & 5 & 5 \\
Odin & 4.620 & 6.24 & 5.798 & 5.553 & 6 & 6 & 6 \\
\hline
\end{tabular}

Note: Price and quality values are not reversed in this table. 
Table 6: The RQ Attributes as Input and Output Variables

\begin{tabular}{ll}
\hline Input attributes & Output attributes \\
\hline Products and services & Emotional appeal \\
Workplace environment & Financial performance \\
Vision and leadership & \\
Social responsibility & \\
\hline
\end{tabular}

variables as shown in Table 6. This results in a four-input, two-output model. (Recall that DEA software allows redefinition of variables in order to study the effect of alternative model forms on reputation ranking.)

In a DEA model, the input variables are commonly seen as costs, which are to be minimized and the outputs are benefits, to be maximized. In the context of understanding reputation, the six attributes need to be considered in a similar manner. Firms create products and services, they influence their workplace environment, vision and leadership with social responsibility are upper management activities and all are prerequisites for functioning. In other words, they are inputs to a process that results in the formation of a reputation. On the other hand, emotional appeal and financial performance are elements of how others outside the firm assess the functioning of the firm; in a sense, they are outputs. These can be seen as the outcomes upon which a reputation assessment is based. Others may interpret these attributes in a different way. What is important is that the inputs and outputs interact within the 'black box' of the firm to create a reputation. Furthermore, what goes on inside the box is a complex transformation process; the attribute weights provide additional information about the values that guide the process. Managerial judgment and understanding of the dynamic architecture that guides resource decisions are the other aspects that the DEA method supports.
With this input-output classification, the attributes can be used as the basis for a DEA performance assessment. The unavailability of the RQ data prevents a more realistic example, but what can be hypothesized is that the relative efficiency measure from the DEA is correlated with the $\mathrm{RQ}$, as indicated by the results presented in Table 5. A comprehensive comparison of the two methodologies would involve performing a DEA study on a full industry. The relative efficiency-RQ correlation can be tested easily and the additional information regarding the attribute weights can be used as the starting point for in-depth case studies of selected firms.

\section{DISCUSSION AND IMPLICATIONS}

Through this example, it has been shown that the DEA methodology is an alternative approach to investigating organizational performance, as reflected through an efficiency measure and specifically how it can utilize the RQ attributes and generate a rating that is similar to the standard $R Q$ analysis. A question that naturally arises from this type of analysis is: 'what is the additional benefit?' given that the RQ is so well established in the field.

One potential response derives from the nature of the DEA methodology. It is a non-parametric, frontier analysis that makes no assumptions regarding the distribution of the underlying data. As a frontier analysis method, DEA focuses managerial attention on learning from the outliers. In 
this case, these observations represent the 'best practice' firms with respect to the reputation attributes. The DEA methodology places no requirements on the data used in the analysis. Although the RQ attributes are all dimensionless, additional information (financial, human resources etc) could also be included in the analysis.

Reputation is clearly an intangible resource of considerable value. One of the characteristics of valuable resources is that there is a degree of causal ambiguity associated with them (Roberts and Dowling, 2002). That is, exactly how the resource is affected by managerial and organizational characteristics is unclear. This is one of the key differences between the structural equation modeling-based RQ methodology and the DEA-based approach presented here. In the authors' view, the nonparametric basis of DEA, which makes no assumptions about the underlying data or the form of the production function, make it a realistic way to represent the results of the causally ambiguous processes that result in a firm's perceived reputation. The resulting attribute weights should be used to encourage managerial discussion surrounding the actual processes that result in the reputation score. Further, the ability of DEA to be linked to other studies, as indicated previously, make this a tool that enables reputation to be treated in an integrated manner.

Of course, the results of a DEA study must be viewed in a critical context because it views the organization as a black box and says nothing about the relationships that generate the observed attribute behaviors. The lack of commitment to a specific causal model might be seen as a weakness of the methodology. The authors feel, however, that approaching the results of the analysis with quantitative data, but with a tabula rasa with respect to the processes for producing the results, serves to prevent managers from framing with, and anchoring their discussion to, only the specific analysis model. Organizations are complex entities and managerial dialogue must be allowed to expand to encompass additional factors. DEA's flexibility and ease of use with regard to respecifying the model serves this way of thinking well. The method thus becomes a decision support tool.

\section{CONCLUSIONS}

As the example used here shows, DEA yields a measure, the relative efficiency, which can be used in a manner similar to the RQ to establish a performance ranking. If that were all that DEA had to offer there would be little reason for proposing it as a performance measure. The DEA approach, however, gives more information, in the form of the weights associated with the variables, as well as the possibility of redefining the analysis model to understand better the attributes' effect on reputation performance. Together, these features of DEA make it a useful technique for ranking, as well as for guiding managerial inquiry into the reasons for performance levels.

The importance of measurement is beyond doubt, as succinctly expressed by Yankelovich (1972) in the opening quotation. Increasing emphasis on softer measures of organizational performance only serves to point out the challenges of developing tools for addressing this important aspect of a firm's operations. The RQ is an established tool for addressing one important intangible resource - a firm's reputation. It indicates to firms what areas they need to work on to improve their reputational ranking. This paper argues that the DEA can indicate to management what can actually be done to improve their firm's performance using this resource.

The approach to investigating reputation proposed in this paper, the DEA methodol- 
ogy, will contribute to the work on organizational reputation in several ways. First, it introduces a powerful methodological approach that is uniquely suited for analyzing the type of data that characterizes reputation measurements. Secondly, the results of a DEA study provide important and valuable insights as to how organizations implicitly weight the variables that are selected in the model as the basis for the analysis. This allows a more direct and detailed comparison of the organizations and can serve as a starting point for more in-depth studies of how firms manage their reputations. Finally, DEA provides a framework for benchmarking and monitoring changes in firms' reputation measurements over time. The dynamic behavior of a firm's reputation may then be linked to managerial or other types of performance that can lead to better understandings of how reputation is formed, developed or lost.

This paper has illustrated the methodology with a small example that indicates how the technique can be applied. The authors propose that the six attributes that form the basis of the RQ can be thought of as inputs and outputs that are related to organizational behavior and performance. The DEA method then allows direct comparisons of how firms implicitly weight the attributes and what effect this has on the perceived efficiency of usage, which may be compared with the RQ index. The extensive application of DEA to the general issue of performance measurement assures a solid theoretical and empirical basis for applying this method to the strategic management of reputation.

\section{ACKNOWLedgments}

The authors wish to thank the two anonymous referees for their thought-provoking comments, suggestions and encouragement.

\section{Note}

1 The Norwegian Customer Barometer (www.kundebarometer.com) is based on the 1988 work in Sweden by Professor Claes Fornell. Professor Fornell's work led to similar national indices in countries such as the USA, Germany, Denmark and Taiwan. See the American Customer Satisfaction Index's (ACSI) web page (www.theacsi.org) for an illustration of the basic model.

\section{References}

Barney, J. (1991) 'Firm resources and sustained competitive advantage', Journal of Management, 17(1), 99-120.

Barney, J. (1996) Gaining and Sustaining Competitive Advantage, Addison-Wesley Publishing, Reading, MA

Bendheim, C.L., Waddock, S.A. and Graves, S.B. (1998) 'Determining best practice in corporate-stakeholder relations using data envelopment analysis', Business and Society, 37(33), 306-339.

Boussofiane, A., Dyson, R.G. and Thanassoulis, E. (1991) 'Applied data envelopment analysis', European Journal of Operational Research, 52(1), 115.

Bromley, D. (2002) 'Comparing corporate reputations: League tables, quotients, benchmarks or case studies?', Corporate Reputation Review, 5(1), 35-50.

Charnes, A., Cooper, W.W. and Rhodes, E. (1978) 'Measuring the efficiency of decision making units', European Journal of Operational Research, 2(6), 429-444.

Charnes, A., Cooper, W.W., Lewin, A.Y. and Seiford, L.M. (eds) (1994) Data Envelopment Analysis Theory, Methods and Applications, Kluwer Academic, Boston, MA.

Chilingerian, J.A. (1994) 'Exploring why some physician's hospital practices are more efficient: Taking DEA inside the hospital', in Charnes, A., Cooper, W.W., Lewin, A.Y. and Seiford, L.M. (eds) Data Envelopment Analysis Theory, Methods and Applications, Kluwer Academic, Boston, MA.

Dierickx, I. and Cool, K. (1989) 'Asset stock accumulation and sustainability of competitive advantage', Management Science, 35(12), December, 1504-1511.

Dowling, G. (2001) Creating Corporate Reputations, Oxford University Press, New York, NY.

Doyle, J.R. and Green, R. (1994) 'Efficiency and cross-efficiency in DEA: Derivations, meanings and uses', Journal of the Operational Research Society, 45(2), 567-578.

Fombrun, C.J., Gardberg, N.A. and Sever, J.M. (2000) 'The Reputation Quotient: A multi-stake- 
holder measure of corporate reputation', The Journal of Business Management, 7(4), 241-255.

Fornell, C. (1992) 'A national customer satisfaction barometer: The Swedish experience', Journal of Marketing, 56(1), 6-22.

Johnson, M.D., Gustafsson, A., Andreassen, T.W., Lervik, L. and Jaesung, C. (2001) 'The evolution and future of national customer satisfaction index models', Journal of Economic Psychology, 22(2), 217-246.

Kay, J. (1996) Foundations for Corporate Success, Oxford University Press, New York, NY.

Keller, K.L. (1998) Building, Measuring and Managing Brand Equity, Prentice Hall, Upper Saddle River, NJ.

Low, J. and Kalafut, P.C. (2002) Invisible Advantage, How Intangibles Are Driving Business Performance, Perseus Publishing, Cambridge, MA.

Norwegian Customer Satisfaction Barometer (2002) www.kundebarometer.com.
Roberts, P.W. and Dowling, G.R. (2000) 'Reputation and sustained superior financial performance', Academy of Management Proceedings, 1-7.

Roberts, P.W. and Dowling, G.R. (2002) 'Corporate reputation and sustained superior financial performance', Strategic Management Journal, 23(12), 1077-1093.

Seiford, L.M. (1990) 'A bibliography of data envelopment analysis (1978-1990)', Department of Industrial Engineering and Operations Research, The University of Massachusetts, Amherst, MA.

Wernerfelt, B. (1984) 'A resource-based view of the firm', Strategic Management Journal, 5(2), 171180.

Yankelovich, D. (1972) Corporate Priorities: A Continuing Study of the New Demands on Business, D. Yankelovich Inc., Stamford, CT. 
Copyright of Corporate Reputation Review is the property of Henry Stewart Publications and its content may not be copied or emailed to multiple sites or posted to a listserv without the copyright holder's express written permission. However, users may print, download, or email articles for individual use. 